$41 \mid 2012$

New perspectives on genericity at the interfaces

\title{
Habituals with indefinite singular objects: aspect and modality
}

Svetlana Vogeleer

\section{(2) OpenEdition \\ 1 Journals}

Electronic version

URL: http://journals.openedition.org/rlv/2133

DOI: $10.4000 /$ rlv.2133

ISSN: 1958-9239

Publisher

Presses universitaires de Vincennes

Printed version

Date of publication: 1 September 2012

Number of pages: 191-214

ISBN: 978-2-84292-350-1

ISSN: 0986-6124

\section{Electronic reference}

Svetlana Vogeleer, « Habituals with indefinite singular objects: aspect and modality », Recherches linguistiques de Vincennes [Online], 41 | 2012, Online since 01 September 2014, connection on 22 April 2019. URL : http://journals.openedition.org/rlv/2133; DOI : 10.4000/rlv.2133 


\title{
Svetlana VOGELEER
}

\section{Institut Libre Marie Haps \& Centre de Linguistique,} Université Libre de Bruxelles

\section{HABITUALS WITH INDEFINITE SINGULAR OBJECTS: ASPECT AND MODALITY ${ }^{1}$}

\begin{abstract}
The object of this study is bare habituals with indefinite singular objects. The term bare habituals denotes those habituals that do not contain adverbials of quantification. On the basis of these sentences, it will be argued that the class of habituals consists of two different groups: quantificational habituals and nonquantificational habituals. The paper accounts for the differences between these two types at the extensional level in terms of their interaction with viewpoint aspect, and at the intensional level in terms of their respective modal component responsible for the generalization.
\end{abstract}

\section{KEYWORDS}

Bare habituals, indefinite singular object, generic quantifier, verbal plurality, aspect, modal quantification, ordering source.

1. I am grateful to the audience of the conference "Genericity: From Morphology to Cognition" and the anonymous reviewer for discussion, comments and advice. 


\section{Introduction}

This paper deals with bare habituals with indefinite singular objects (IS). Bare habituals are defined as habituals that do not contain adverbials of quantification, frequency or cyclicity. The IS of these sentences is bare, that is unmodified, as well. I will argue that there are two types of habituals: quantificational habituals and non-quantificational habituals. A quantificational habitual reading arises when the sentence itself offers a tripartite quantificational structure. Non-quantificational habitual sentences have a binary structure.

All habituals share two properties: the extensional property of the event iteration and the intensional property of generalization associated with stativization. I will argue that the way in which these properties are realized depends on whether the habitual reading is quantificational or not.

In section 2, I will argue that the two most influential analyses of habituals in the literature, viz. Krifka's et al. (1995) quantificational analysis and Kratzer's (2007) non-quantificational analysis, offer a satisfactory account of either quantificational habituals or non-quantificational habituals, but neither of them accounts for the whole class of habituals.

The issue addressed in section 3 is the interaction of each type of habitual with the viewpoint aspect. It will be shown that while non-quantificational habituals are compatible with perfective aspect, bare quantificational habituals are not. I will argue that the covert quantifier in the latter type is licensed by imperfective aspect.

Sections 4 and 5 account for the modal component of each of the two types of habituals. I will argue that the modal quantifier of quantificational habituals is nothing but GEN, that is, the same operator as in generic sentences. As for non-quantificational habituals, I propose that their implicit modal is a stativizing operator STATE, which can take two different forms: inductive or deductive.

\section{Non-quantificational and quantificational habituals with indefinite singular objects}

Habituals have been analysed in different ways in the literature, the quantificational analysis (Krifka et al. 1995) and non-quantificational analysis (Kratzer 2007, Boneh \& Doron 2008, 2010) being the most influential approaches.

The quantificational analysis assumes that the habitual operator is a subtype of generic quantifier with universal or quasi-universal quantificational force quantifying over a set of situations provided by the context. With bare habituals, the habitual operator is a kind of covert adverbial with quasiuniversal force, something like usually. This assumption accounts for the fact 
that habitual sentences allow for exceptions, which means that the predicate is not required to hold in all situations for the sentence to be true. As the focus of this study is on bare habituals, that is, habituals with no adverbials of quantification, the quantificational analysis will be abbreviated as "covertquantifier" analysis.

The non-quantificational analysis (henceforth "verbal-plural analysis") assumes that the basic extensional component of habituality, viz. iterativity, is not related to quantification (Kratzer 2007, Boneh \& Doron 2008, 2010). Iterativity, that is plurality of events, is provided by the lexical verbs themselves since "verbs are born as plurals" (Kratzer 2007). In other words, verbs are assumed to denote Linkian sums (Link 1983), that is, sums of events consisting of at least one event. On this view singularity is considered to be a "special case" of plurality.

In this section, I will argue, on the basis of sentences with indefinite singular (IS) objects, that there are two types of bare habituals, nonquantificational habituals and quantificational habituals, and that each of the two analyses offers a satisfactory account of one of the two types. Yet, neither of them accounts for both. In my analysis, I will concentrate on the temporal notion of event recurrence, putting aside the aspectual and modal components of habituals.

Non-quantificational habituals are illustrated in (1). We will assume that sentences in (1) have a binary structure in which the VP conveys the informational focus: $[\mathrm{NP}]_{\text {top }}[\mathrm{VP}]_{\text {inf.foc. }}$. The French present tense is ambiguous between an episodic (here progressive) reading and a habitual reading. However, as the focus is here on the habitual reading, this is the only one that will be taken into account in the English translation. In (1a), the VP denotes an activity-like accomplishment, i.e. an event type that can be viewed either as an accomplishment or an activity, which is typical, among others, of cleaning verbs (Mittwoch 2005). ${ }^{2}$ In (1b), the VP unambiguously denotes an activity. The IS of $(1 \mathrm{a}, \mathrm{b})$ appears as taking a wide scope, i.e. Mary cleans the same garage throughout the whole event. In (1c), where the event type is a "onceonly" accomplishment, the habitual reading is blocked by the wide scope of the IS since the event cannot be iterated with the same object.

(1) a. Marie nettoie un garage.

(EPIS/HAB)

Mary cleans a garage.

b. Jean escorte un ministre.

(EPIS/HAB)

John escorts a minister.

c. Marie mange une pomme / fume une cigarette. (EPIS/*HAB)

Mary *eats an apple /*smokes a cigarette.

2. A list of ambiguous accomplishments is proposed e.g. in Kratzer (2004: 386). 
The second type, quantificational habituals, is illustrated in (2). The sentences in (2) contrast with those in (1) in that they are compatible with telic event types, including "once-only" accomplishments $(2 \mathrm{c}) .^{3}$
a. Marie mange une pomme avec une fourchette.
(EPIS/HAB) Mary eats an apple with a fork.
b. Marie fume une cigarette sans avaler la fumée.
(EPIS/HAB)
Mary smokes a cigarette without inhaling the smoke.
c. Marie /MANge/ une pomme, elle ne la jette pas (comme toi).
Mary /EATS/ an apple, she does not throw it away (like you do).

\subsection{Quantificational habituals}

The sentences in (2) differ from those in (1) in that they provide themselves a restrictor for a quantifier over situations ( $c f .(3)$, (4) below) since the IS is followed by a sentence-final adjunct (a manner adverbial, a PP) which takes over the function of focus. As a result, the IS in the middlefield is distressed (Büring 2001). It is mapped onto the restrictor of some quantifier where it acquires quantificational variability while the adjunct goes into the nuclear scope. As the restrictor providing a set of situations is available, the sentence triggers the inference that there is a covert quantifier as well. The denotation in (3) is a provisional paraphrase; the shortcomings of paraphrasing the restrictor by a when-clause will be accounted for in section 4 .

$$
\text { usually }_{\mathrm{s}}\left[(\text { when Mary eats an apple) })_{\mathrm{s}}\right] \text { (she eats it with a fork in s) }
$$

The configuration in (2c) yields the quantificational structure in (4), in which the covert adverbial quantifies over alternatives ( $c f$. e.g. Cohen 2003). This structure is available if the sentence exhibits a narrow focus in the middlefield (Büring 2001), so that the sentence-final IS turns out to be distressed and goes into the restrictor.

$$
\text { usually }_{\mathrm{s}}\left[\text { what Mary does }{ }^{\mathrm{A}}\right. \text { (when she has an apple)] (is eat it in s) }
$$

The "covert-quantifier" analysis properly captures the meaning of quantificational habituals. However, it is not applicable to non-quantificational habituals. In sentences offering a tripartite stricture, the reading does not change dramatically if the covert quantifier is made overt as in (5), particularly in sentences with "once-only" predicates, where the adverbial necessarily

\footnotetext{
3. In Ferreira $(2004,2005)$, a distinction is made between bare habituals and quantificational habituals. Note that the former term applies to sentences with no adverbials while the latter applies to sentences with adverbials of quantification. The habituals I am interested in are all bare in the sense that they are free of adverbials of quantification, frequency or cyclicity.
} 
scopes over the IS ( $c f$. note 4 below). The only difference between the French sentence in (2b) and that in (5) is that the overt adverbial blocks the episodic (progressive) reading.

Marie fume souvent une cigarette sans avaler la fumée. (*EPIS/HAB) Mary often smokes a cigarette without inhaling the smoke.

By contrast, the addition of an overt adverbial to non-quantificational habituals cancels the ban on telic predicates (6). I take this fact as an additional argument in support of the claim that sentences of type (1) do not yield a covert quantifier (cf. Ferreira 2004 for some other arguments).
a. Marie mange une pomme. Mary * eats an apple.
b. Habituellement, Marie mange une pomme.
Mary usually eats an apple.
c. usually $\mathrm{s}_{\mathrm{s}}\left[(\text { when Mary is hungry })_{\mathrm{s}}\right]$ (she eats an apple in s)

While (1a) and (1b) do not require any restrictor, in (6b), the overt adverbial requires a set of plausible situations, as in $(6 b, c)$, even if such situations are not provided overtly by the context. The habitual reading is blocked in (6a) because this reading requires that the IS take a wide scope. This requirement does not hold for (6b), where the IS has a narrow scope. As a result, the whole VP is mapped onto the nuclear scope of the quantifier. ${ }^{4}$

\subsection{Non-quantificational habituals}

Kratzer's (2007) analysis of iterativity offers a suitable framework for the analysis of non-quantificational habituals. The analysis assumes that the iteration of events, which constitutes the basis of habituality, amounts to the Linkian sum operator ( $\sigma)$ (Link 1983).

$$
\begin{aligned}
& \lambda \mathrm{P} . \lambda \mathrm{e}\left[\mathrm{P}(\mathrm{e}) \& \mathrm{e}=\sigma \mathrm{e}^{\prime}\left[\mathrm{P}\left(\mathrm{e}^{\prime}\right) \& \mathrm{e}^{\prime} \subset \mathrm{e}\right]\right] \\
& \text { where } \subset \text { indicates that } \mathrm{e}^{\prime} \text { is a proper subpart of } \mathrm{e} .
\end{aligned}
$$

The sum operator is provided by the verb as an intrinsic verbal feature of cumulativity (verbal plurality). Cumulative plurality does not exclude singularity since a sum can consist of one single item. The crucial point is that

4. If the predicate is not "once-only", the IS manifests scope ambiguity with respect to the adverbial. It can be interpreted as either having a narrow scope (ia), which results in different office buildings, or as taking a wide scope over the quantifier (ib), and as a result only one single office building is being referred to.

(i) Mary usually cleans an office building.

a. usually ${ }_{\mathrm{s}}$ [(when M. needs money) $]$ (she cleans an office building in $\mathrm{s}$ )

b. $\quad \exists x$ office_building $(\mathrm{x}) \&$ usually $_{\mathrm{s}}[$ (when M. works) $]$ (she cleans $\mathrm{x}$ in s) 
the verbal sum operator is scopeless. Thus, within Kratzer's framework, the fact that the IS in (1) appears as taking wide scope is not due to the IS quantifier raising over some covert habitual quantifier, as proposed e.g. in Rimell (2004), but simply to the scopelessness of the sum operator, which is not able to distribute an IS object. ${ }^{5}$ On this account, (1a) is represented as follows:

$$
\begin{aligned}
& \lambda \text { e. } \exists x\left[\operatorname{garage}(\mathrm{x}) \& * \operatorname{clean}(\mathrm{M}, \mathrm{x}, \mathrm{e}) \& \mathrm{e}=\sigma \mathrm{e}^{\prime} \exists \mathrm{x}\left[\operatorname{garage}(\mathrm{x}) \& *^{*} \operatorname{clean}\left(\mathrm{M}, \mathrm{x}, \mathrm{e}^{\prime}\right)\right.\right. \\
& \left.\left.\& \mathrm{e}^{\prime} \subset \mathrm{e}\right]\right] \\
& \text { where the Linkian star-operator }(*) \text { indicates that the verb is plural. }
\end{aligned}
$$

According to (8), there is an eventuality e of Mary cleaning some garage which consists of eventualities e' (proper parts of e) of Mary cleaning a garage. Given that the sum of eventualities contains just one garage, the garage is the same in each part-event (Kratzer 2007). For the sake of clarity, I will use the term "apparent wide scope" for the IS.

The verbal-plural analysis properly accounts not only for sentences with IS but also for other kinds of non-quantificational habituals, namely sentences with purely verbal atelic predicates (9a), predicates with weak definites (9b) (Carlson 2006) and with plurals, whose existential reading in (9c) is marked in French by the indefinite plural determiner des. Like the English existential bare plurals, des-plurals turn telic events into atelic ones. However, (9c) differs from (9a) and (9b) in that existential bare plurals and des-plurals are able to distribute the whole eventuality over situations ( $c f$. Kratzer 2007). This implies that $(9 \mathrm{c})$ can give rise to a quantificational reading as well, which is not the case in (9a) and (9b) ( $c f$. section 5). In what follows, my analysis does not take into account sentences with existential bare plurals and des-plurals.

$$
\begin{aligned}
& \text { a. Marie fume. } \\
& \text { Mary smokes. }
\end{aligned}
$$

5. The sentences in (i) with activity-like VPs seem to contradict what is said in the text. Their habitual reading does not require that the same hat and the same bus be involved in all occurrences of the event ( $c f$. on similar cases Kleiber 1987: 162; Laca 1990).

(i) a. Marie porte un chapeau.

Mary wears a hat.

b. Jean conduit un bus. John drives a bus.

As pointed out in Laca (1990), in cases like those in (i) there is a close lexical relationship between the noun and the verb. The IS in (i) manifests some typical properties of incorporated nominals, viz. the indefinite is non-specific rather than specific; it is interpreted as a narrow-scope indefinite, showing no scope interaction with other operators in the sentence; the whole clause shows a lesser degree of transitivity ( $c f$. e.g. Carlson 2006). The fact that the verbal sum operator extends over the IS in (i) is an additional argument for treating these IS as cases of pseudo-incorporation (semantic incorporation) in which the indefinite determiner is not cardinalized. 
b. Jean joue du piano.

John plays $D U \_$piano.

c. Jean mange des pommes.

John eats DES_apples.

As shown in (9), non-quantificational habituals are sentences with atelic predicates. Bare habituals with telics require a quantificational analysis, that is, they need either a contextually provided restrictor (10a) or a contextually given cyclic iteration phrase, e.g. after dinner, at eight, in the morning, etc. (10b).

(10) a. Marie prend le train.

Mary takes the train. (e.g. when M. goes to the office, she takes the train)

b. Marie part tôt.

Mary leaves early. (e.g. M. leaves early in the morning (=almost every morning))

Summing up, I have argued, on the basis of sentences with IS objects, that there are two types of bare habituals, which require different analyses. While the "covert-quantifier" analysis (Krifka et al. 1995) properly accounts for quantificational bare habituals, the "verbal-plural" analysis (Kratzer 2007) is suitable for non-quantificational habituals.

\section{Bare habituals and viewpoint aspect}

\subsection{Non-quantificational habituals and perfective viewpoint aspect}

Habituality is traditionally associated with imperfectivity. For instance, Lenci \& Bertinetto (2000) argue that the Italian compound past, which conveys perfective viewpoint aspect (henceforth "vp-aspect"), allows an iterative reading but not a habitual reading. Ferreira $(2004,2005)$ claims that habituality amounts to imperfectivity of plural VPs. Boneh \& Doron $(2008,2010)$, by contrast, propose an analysis in which the habitual operator is a modifier adjoined to the VP and, as such, is independent of aspect. The authors argue ( $c f$. especially Boneh \& Doron 2010) that the habitual reading is compatible with perfective viewpoint aspect.

Leaving aside the modal component of habituals, I will argue in this section that non-quantificational habituals are compatible with perfective vpaspect. By contrast, bare quantificational habituals are licensed by imperfective vp-aspect.

I will assume a definition according to which imperfective and perfective vp-aspects are defined in terms of a relation between the temporal trace of the event $\tau(e)$ and some interval $t$. Imperfective aspect is defined in (11a) as a relation on which $t$ is included into the temporal trace of the event. Perfective 
aspect is defined in (11b) as a relation on which $t$ includes the temporal trace of the event.

$$
\begin{array}{ll}
\text { a. } & {[\mathrm{IMP}]=\lambda \mathrm{t} \cdot \lambda \mathrm{P} . \exists \mathrm{e}[\mathrm{P}(\mathrm{e}) \& \mathrm{t} \subseteq \tau(\mathrm{e})]=1} \\
\text { b. }[\mathrm{PFV}]=\lambda \mathrm{t} . \lambda \mathrm{P} . \exists \mathrm{e}[\mathrm{P}(\mathrm{e}) \& \tau(\mathrm{e}) \subseteq \mathrm{t}]=1
\end{array}
$$

It follows from (11a) and (11b) that the temporal trace of the event is an unbounded interval under imperfective vp-aspect, while perfective vp-aspect imposes boundaries on this interval. Perfective aspect is expressed in French by the compound past (passé composé, PC). ${ }^{6}$ Imperfective vp-aspect in the past is conveyed by the imparfait, while the present is inherently imperfective.

It has been observed by e.g. Comrie (1976), Dahl (1995) that in languages which distinguish between perfective and imperfective aspect, habitual meaning is mostly conveyed by imperfective verb forms. Yet, there is no reason for not assigning a habitual reading to non-quantificational habituals like those in (12a). The habitual reading of (12a) appears if the lexical VP (garder un enfant / to look after a child) is interpreted in the sense that Mary is a babysitter, that is, if we suppose that the event consists of a plurality of events of Mary looking after a child. The habitual in (12a) behaves in the same way as a sentence with purely stative predicates (12b), whose compatibility with perfective vp-aspect is non-controversial. The predicate of (12b) is purely stative since it does not allow a reading on which the event consists of a plurality of events of Mary running a company. In the same way as with the present tense, the IS in (12a) has "apparent wide-scope"; the IS of (12b) has a wide scope tout court (cf. 2.2).

(12) a. Marie a gardé un enfant (pendant deux ans).

Mary looked.PC after a child (for two years).

b. Marie a dirigé une entreprise (pendant cinq ans).

Mary ran.PC a company (for five years).

For time-measure phrases impose the passé composé (PC) since the imparfait is incompatible with a bounded temporal trace of the event. ${ }^{7}$ In order for a sentence to get a habitual reading it must satisfy two requirements: the running

6. The French passé composé allows both a perfective reading and a perfect reading. The latter reading will not be taken into account here.

7. In Russian, and in other Slavic languages, perfective aspect is incompatible with for time-measure phrases. Being a morpho-lexical category, Russian perfective aspect brings about not only perfective vp-aspect in the sense defined in (11b) but also telicity and singularity of the event. As for morpho-lexical imperfective aspect, it is unmarked for viewpoint aspect, i.e. it is compatible with both vp-aspects. It follows that habituality is expressed by imperfective aspect irrespectively of whether the interval corresponding to the temporal trace of the event is bounded or unbounded. 
time of the event must be sufficiently long and the underlying activity must be discontinuous.

(13) a. Marie a nettoyé un garage pendant deux jours.

Mary cleaned.PC a garage for two days.

b. Marie a nettoyé un garage pendant pendant deux ans.

Mary cleaned.PC a garage for two years.

c. Marie a dormi pendant deux jours / pendant deux ans.

Mary slept.PC for two days / for two years.

In (13a), the time interval is measured in days; this does not give rise to a habitual reading but only to an episodic reading. Apparently, in order to be judged as being a past habit that is no longer the case at the time of speech, a recurrent activity must last at least for some months, in the most unmarked case for some years, as it is the case in (13b). As we will see below in (14), this requirement does not hold when the aspect is imperfective. Under perfective aspect, when the time span is not specified, choosing between an iterative episodic reading and a habitual reading results from a contextual inference concerning the length of the time span.

The truth conditions of the habitual reading under perfective aspect differ from those under imperfective aspect. Sentence (14a) will be false on the habitual reading if uttered by someone who saw Mary smoke on one or even a few particular occasions. With imperfective aspect, for instance when the present is used, a few events or even one single episodic event may be sufficient for the habitual sentence to be true. For instance, (14b) is interpreted as habitual when uttered in this context despite the fact that the number of episodic events is quite small. In a similar way, the sentence in (14c) gets a habitual reading even if the Prime Minister dyed his hair for the first time yesterday. The difference between requirements on truth conditions under perfective (14a) and imperfective $(14 b, c)$ aspect will be accounted for in section 5 .

(14) a. Marie a fumé. C'est pour ça qu'elle a un cancer de poumon maintenant. Mary smoked. That's why she has a lung cancer now.

b. Marie fume, je t'assure. Je l'ai vue fumer hier à la fête. Mary smokes, I assure you. I saw her smoke yesterday at the party.

c. Regarde! Notre premier ministre se teint les cheveux. Look! Our Prime Minister dyes his hair.

In (13a), the episodic reading triggers the pragmatic inference that Mary's activity is not continuous. According to our reasonable expectations, there must be some pause-stages for sleeping, eating, etc. In (13b), in which the reading is habitual since the length requirement on the time span is met, there are similar reasonable expectations guiding the inference of pause-stages. Moreover, the habitual reading in (13b) triggers an additional pragmatic inference: Mary's 
activity is judged to be a professional occupation. The reasons behind this inference will be examined in section 5 .

In (13c), we have no reasonable expectations as to what constitutes a "normal" pause-stage when the activity is sleeping. As a result, the predicate appears to denote a continuous activity not only when the interval is measured in days but also when it is quite long. When perfective aspect combines with an activity, it is not possible to determine whether there is just one activity stage or more than one. The predicate denotes a sum consisting of at least one activity stage. The ways in which the activity stages alternate with pausestages are determined by pragmatic inferencing.

The conclusion is that, as far as non-quantificational habituals are concerned, Boneh \& Doron's (2010) claim seems to be right. This type of habituals appears to be fully compatible with perfective vp-aspect. However, the requirements on truth conditions concerning the length of the interval hold only under perfective aspect. Under imperfective aspect, the number of episodic events, their frequency and the length of the interval are not part of the truth conditions ( $c f$. section 5).

\subsection{Quantificational habituals and the perfective viewpoint aspect}

Things change dramatically when perfective aspect combines with quantificational habituals. Perfective aspect in (15b) and (16b) deprives (15a) and (16a) of the tripartite quantificational structure which characterizes them under imperfective aspect, irrespective of whether the present is used or the imparfait.

(15) a. Marie fume / fumait une cigarette sans avaler la fumée.

Mary smokes/smoked.IMP a cigarette without inhaling the smoke.

b. *Marie a fumé une cigarette sans avaler la fumée pendant deux ans.

Mary smoked. $P C$ a cigarette without inhaling the smoke for two years.

(16) a. Marie /MANge//manGEAIT/ une pomme, elle ne la jette/jetait pas.

Mary /EATS/ /ATE.IMP/ an apple, she does not /did.IMP not throw it away.

b. *Marie a /manGÉ/ une pomme, elle ne l'a pas jetée pendant deux ans. Mary /ATE.PC/ an apple, she did not throw it away for two years.

Sentences (15b) and (16b) do not yield any covert quantifier and thus behave as non-quantificational habituals, that is, their IS has "apparent wide scope": Mary smoked the same cigarette and ate the same apple for two years. If the sentence does not contain a for-phrase, it allows only a non-iterative episodic reading.

Perfective aspect is an existential quantifier over events and intervals. It locates the whole event in the actual world ( $c f$. section 5). Being lexical, verbal 
plurality is preserved inside the interval corresponding to the temporal trace of the event. As for the IS, it loses its quantificational variability. The denotation in (17) follows Kratzer's (2007) proposal discussed in 2.2 according to which the IS does not undergo quantifier raising. It has an "apparent wide scope": given that the sum of events contains just one cigarette, the cigarette is the same in each part-event.

$$
\begin{aligned}
& \lambda \mathrm{t} . \lambda \mathrm{e} . \exists \mathrm{x}\left[\operatorname{cigarette}(\mathrm{x}) \& *_{\operatorname{smoke}}(\mathrm{M}, \mathrm{x}, \mathrm{e}) \& \tau(\mathrm{e}) \subseteq \mathrm{t} \& \mathrm{t}<\mathrm{t}_{0} \& \mathrm{e}=\right. \\
& \left.\sigma \mathrm{e}^{\prime} \exists \mathrm{x}\left[\operatorname{cigarette}(\mathrm{x}) \& * \operatorname{smoke}\left(\mathrm{M}, \mathrm{x}, \mathrm{e}^{\prime}\right) \& \mathrm{e}^{\prime} \subset \mathrm{e}\right]\right] \\
& \text { where } \mathrm{t}_{0} \text { is the time of speech. }
\end{aligned}
$$

Quantification under perfective aspect can only be imposed by either explicit quantificational adverbials (18a) or cyclic iteration phrases (18b). Cyclic iteration phrases (after dinner, on Sunday, at twelve, etc.) are quantifiers as well ( $c f$. Landman \& Rothstein 2010). They distribute the object over situations located at cyclic time intervals.

a. Marie a toujours/souvent fumé une cigarette très lentement (\#pendant deux ans).

Mary has always/often smoked a cigarette very slowly (\#for two years).

b. Marie a fumé une cigarette après le dîner / le dimanche pendant trois ans. Mary smoked a cigarette after dinner /on Sunday for three years.

The conclusion is that the covert quantifier in quantificational habituals is licensed by imperfective vp-aspect (15a), (16a). I will assume in section 4 that the covert quantifier is modal and its modality is related to imperfective aspect. As for the quantification by overt adverbials under the scope of perfective aspect, I follow Portner's (2009, Ch. 4: 4.4.2) view according to which quantificational adverbials per se do not quantify over worlds but only over "counting situations". They are not able to quantify over worlds as worlds are maximal situations which are not parts of any other situation (Kratzer 1989). Under imperfective aspect, quantification over worlds is licensed by the unboundedness of the interval corresponding to the temporal trace of the event: it is not due to the adverbial as such ( $c f$. section 4).

The question raised by Boneh \& Doron's (2008, 2010) claim and addressed in this section has been whether habituals are compatible with perfective vp-aspect or not. As far as non-quantificational habituals are concerned, the answer is positive in the sense that the reading of their IS is the same under perfective aspect as under imperfective aspect (but see section 5). By contrast, bare quantificational habituals with IS objects lose their tripartite quantificational structure, and hence their covert quantifier, and become nonquantificational under perfective aspect. Their IS acquires "apparent wide scope", the same as it has in non-quantificational habituals. 


\section{Quantificational habituals with IS objects: genericity and circumstantial modality with a deontic flavour}

In this section, I will argue that quantificational habituals meet the central claim of the "covert-quantifier" analysis (Krifka et al. 1995; Carlson 1995 ) according to which the habitual operator is nothing but generic modalized quantifier GEN. I assume that GEN consists of two components, one of which is extensional and the other intensional (modal). Sections 4.1. and 4.2. give an account of these two components.

\subsection{Genericity}

The tripartite structure of quantificational habituals is the same as in middles, in particular IS generic middles. Condoravdi (1989) claims that middles boil down to either IS generics (19a) or habituals (19b) (but see below).
a. Un poème se lit à haute voix.
(GEN) A poem RP reads loudly.
( $\mathrm{RP}=$ reflexive pronoun)
b. Ce poème se lit à haute voix.
This poem reads loudly.
c. Marie lit un poème à haute voix. $\quad$ (EPIS/HAB) Mary reads a poem loudly.

In both middles $(19 a, b)$ as well as in quantificational habituals $(19 c)$, the tripartite structure is brought about by a sentence final adjunct, typically a manner adverbial, a locative PP or an instrumental PP. In (19a), the generic quantifier GEN quantifies over a set of situations (events) whose Object (Theme, Patient) is denoted by the subject NP. I assume a view according to which the Agent variable is brought about by an implicit argument ( $c f . e . g$. Steinbach 2002 and references therein). This view underlies the analysis given in (20a) in which the three free variables, including the Agent variable, are bound by GEN. I assume that in habitual reading of (19c) the quantifier binding the situation variable and the Object variable is generic (20b) in the same way as in (20a).
a. $\quad \lambda P . \lambda s . \lambda x . \lambda y . \operatorname{GEN}_{x, y s}[\operatorname{Agent}(x) \& \operatorname{poem}(y) \& \operatorname{read}(x, y, s)] \rightarrow$ [loudly $(\operatorname{read}(\mathrm{x}, \mathrm{y}))$ in $\mathrm{s}]$
b. $\lambda$ P. $\lambda s . \lambda x . \operatorname{GEN}_{x, s}[\operatorname{poem}(\mathrm{x}) \& \operatorname{read}(\mathrm{M}, \mathrm{x}, \mathrm{s})] \rightarrow[\operatorname{loudly}(\operatorname{read}(\mathrm{M}, \mathrm{x})$ in $\mathrm{s}]$

On the analysis in (20b), the IS object in quantificational habituals is generic. It is not bounded by the existential quantifier. Within the view that the IS is bounded by the existential quantifier, the IS object of quantificational habituals is not generic but non-specific.

The view that the IS object is bounded by GEN implies that there is no need to postulate a separate quantifier HAB. Postulating HAB implies that 
HAB differs from GEN by establishing a temporal relation (overlap) between two sets of situations. On such an approach, the situations in the restrictor that HAB quantifies over correspond to temporal when-clauses ( $c f$. the paraphrase in section 2.1: when Mary reads a poem, she reads it such and such way). The point is that the IS in a when-clause is non-specific, rather than generic. Its non-specificity is evidenced by the fact that in French a plural object NP in when-clauses is marked by the indefinite plural determiner des, and it is a well-known fact that plural des-indefinites do not allow a generic reading (excepting some focus-induced readings).

Quand Marie lit des poèmes, elle les lit à haute voix. When Mary reads DES poems, she reads them loudly.

The claim that the IS in (19c) is generic rather than non-specific is proven by observations made in Laca (1990) about plurals in French and Spanish. In tripartite sentences, object NPs with a mass noun or a plural noun require a definite singular and a generic definite plural, respectively.
a. Les Chinois mangent du riz. (exist. partitive) LES_Chinese eat DU_rice.
$\mathrm{a}^{\prime}$. Les Chinois mangent le riz $/ *$ du riz avec des baguettes. (def. mass sing.) Chinese eat LE_rice/*DU_rice with chopsticks.
b. Pedro mata cucarachas. (exist. bare pl.) Pedro kills cockroaches.
b'. Pedro/MAta/ a las cucarachas. (gen. def. pl.) Pedro/KILLS/ prep. LAS_cockroaches.

The overt marks of genericity in (22a') and (22b'), which have the same structure as quantificational habituals, prove that the IS object in quantificational habituals is generic, not non-specific. From this it follows that bare quantificational habituals are quantified by GEN; there is no a separate quantifier HAB whose restrictor must by realized as temporally bounded when-clause.

The assumption that both middles and habituals are quantified by GEN does not imply that these two types of sentences are identical. In (20b), the Agent is not represented by a free variable since the Agent is Mary. As the Agent is the instance controlling the event, the truth of bare quantificational habituals requires that there be some verifying instances of the generically quantified event (situation) in the actual world.

In middles, the Agent denoted by an implicit argument is generic in both (19a) and (19b). What is specific in non-generic middles like (19b) is the Object (Theme, Patient) but the Object has no control over the event. As has been repeatedly pointed out in the literature (contra Condoravdi 1989), middles, whether generic (19a) or non-generic (19b), don't require verifying 
instances for the sentence to be true ( $c f$. e.g. Steinbach 2002: 38-39 and references therein).

\subsection{Modality}

It is common knowledge that the generic operator is implicitly modalized in the sense that it quantifies over "normal", that is idealized, worlds (Krifka et al. 1995). Modal properties are also assigned to habituals on the grounds that habituals don't refer to spatiotemporally anchored events (Dahl 1975, Comrie 1976, Carlson 1995). Their modality is typically described as "non-accidentalness" (Dahl 1975) or as "characterizing" (Carlson 1995).

\subsubsection{Perfective aspect and modality}

Modality in the sense of non-accidentalness (Dahl 1975) is supposed to be the main property that distinguishes habituals from iteratives, the latter being viewed as an accidental event recurrence. However, the distinction between these two classes is not self-evident. For instance, the question of whether (23a) describes an accidental event recurrence or a characterizing property of Mary is all the more puzzling that this sentence is wholly compatible with perfective aspect (23b).

(23) a. Marie va à l'école à vélo.

(EPIS/HAB) Mary goes to school by bicycle.

b. Marie est allé à l'école à vélo pendant un an. Mary went. $P C$ to school by bicycle for one year.

As was shown in section 3 , the IS object of quantificational habituals acquires "apparent wide scope", which is indicative of the fact that the sentence loses its covert quantifier. The same holds for generic sentences with IS subjects (24a). A generic IS subject gets a specific reading under perfective aspect (24b).

a. Un garçon ne pleure pas.

A boy does not cry.

b. Un garcon n'a pas pleuré pendant un an.

A boy did. $P C$ not cry for one year.

Sentence (23a) does not contain any IS. Yet, let us suppose that (23a) is quantified by GEN: $\operatorname{GEN}_{\mathrm{s}}[(\mathrm{M}$. goes to school)] $\rightarrow$ [by bicycle in s]. This implies that in (23b), the situation variable is no longer bound by GEN. I claim that quantificational habituals, whether they have an IS object or not, become non-quantificational under the perfective aspect. In other words, although the difference between (23a) and (23b) is invisible, there is no generic quantifier in (23b). As far as quantificational habituals are concerned, Lenci \& Bertinetto's 
(2000) claim that habituals are incompatible with perfective aspect proves to be correct on this view (contra Boneh \& Doron 2008, 2010).

Adding a world component to the definition of perfective aspect in (11b) yields (25), which stipulates that the perfective aspectual operator is an existential quantifier locating the event in the actual world $w$.

$$
[\mathrm{PFV}]=\lambda \mathrm{w} . \lambda \mathrm{t} . \lambda \mathrm{P} . \exists \mathrm{e}[\tau(\mathrm{e}) \subseteq \mathrm{t} \& \mathrm{P}(\mathrm{e})(\mathrm{w})]=1
$$

Assuming that quantificational GEN (henceforth $\mathrm{GEN}_{\mathrm{Q}}$ ) is modal implies that it is incompatible with the operator PERFECTIVE since the latter locates the event in the actual world.

\subsubsection{Quantificational GEN as a modal quantifier}

The denotation in (20b) accounts for the extensional component of $\mathrm{GEN}_{\mathrm{Q}}$. Accounting for modal properties of $\mathrm{GEN}_{\mathrm{Q}}$ requires a modal component. Following Kratzer (1981), I assume that a modal quantifier quantifies over a set of worlds provided by a modal base $(\mathrm{MB}) \cap \mathrm{f}(\mathrm{w})$ (Kratzer's "conversational background") related to the evaluation world w by an accessibility relation. The MB is restricted by an ordering source (OS) $\cap \mathrm{g}(\mathrm{w})$ inducing an ordering on the set of worlds in the MB in terms of their closeness to some ideal set of worlds.

Given that in quantificational habituals GEN is licensed by imperfective aspect, I assume, following Ferreira $(2004,2005)$ and Anand \& Hacquard (2006), that imperfective aspect is inherently modal, both on the progressive and the habitual reading. Its modality follows from the definition given in (11a), that is from the fact that the temporal trace of the event is partly located on the "continuation branch" (Landman 1992) of the time axis starting at the first minimal interval immediately following the inclusion point $\tau(\mathrm{e}) \supseteq \mathrm{t}$. For sentences in the present tense, $t$ is the time of speech $t_{0}$.

I assume that the $\mathrm{MB} \cap \mathrm{f}(\mathrm{w})$ of imperfective aspect is circumstantial (Circ). According to Kratzer (1981), a circumstantial MB (Kratzerian "in view of facts in w") contains those worlds w' in which the circumstances of the event are maximally similar to those in the evaluation world w. For instance, the circumstances of the event of Mary reading a book loudly in $\mathrm{w}^{\prime}$ are maximally similar to those in w. Worlds in the MB are restricted by an ordering source $\cap \mathrm{g}(\mathrm{w})$ to those "best" worlds in which the event is not interrupted (NI), e.g. Mary does not have a soar throat, she is still able to read, etc. ( $c f$. Portner 1998 for the progressive; Ferreira 2004, 2005 for habituals; Anand \& Hacquard 2011 for both). In the case of habituals, $\mathrm{e}^{\prime}$ in (26) is a plurality of e.

(26) $\quad[\operatorname{IMP}(e, P)]^{\mathrm{f}(\mathrm{w}), g(\mathrm{w})}$ is true at $w$ iff for all worlds $\mathrm{w}^{\prime}$ in Best(Circ, NI, e, P) there is an event $\mathrm{e}^{\prime}$ which includes e s.t. $\mathrm{P}\left(\mathrm{e}^{\prime}\right)\left(\mathrm{w}^{\prime}\right)=1$. 
Imperfective aspect allows GEN to quantify over those circumstantial worlds that are located on the "continuation branch" of the time axis, which projects the event into the future.

I propose that the $\mathrm{MB}$ of the modal component of $\mathrm{GEN}_{\mathrm{Q}}$ is the output of the imperfective operator as defined in (26), i.e. the MB is circumstantial, in the same way as in (26), and already restricted to best non-interrupted worlds. As for the ordering source, my claim is that it is an inverse normative OS. Normative ordering sources belong to the family of deontic modalities. A standard normative ordering source (Kratzerian "in view of the Law in w", i.e. rules, norms, etc.) orders worlds in the MB in terms of their closeness to those ideal worlds $\mathrm{w}^{\prime}$ in which some rules that hold in $\mathrm{w}$ are realized. My proposal is that worlds in the $\mathrm{MB}$ of $\mathrm{GEN}_{\mathrm{Q}}$ are restricted to those ideal worlds $\mathrm{w}^{\prime}$ in which some facts that hold in $\mathrm{w}$ are rules/norms, while they are not necessarily rules/ norms in w. Given that a rule (norm) is a stative entity, the inverse normative ordering source accounts for stativizing properties of $\mathrm{GEN}_{\mathrm{Q}}$. Moreover, the OS also accounts for the (inverse) normative flavour of quantificational habituals since it yields at the outcome a set of worlds in which reading a poem loudly or going to school by bicycle is a norm for the Agent (Mary). GEN ${ }_{Q}$ universally quantifies over worlds in the MB restricted by the inverse normative OS.

$\left[\mathrm{GEN}_{\mathrm{Q}} \cap \mathrm{f}(\mathrm{w})^{\cap \mathrm{g}(\mathrm{w})}\right]$ is defined iff $\cap \mathrm{f}(\mathrm{w})$ is Best(Circ,NI) and $\cap \mathrm{g}(\mathrm{w})$ is inverse normative.

$\left[\mathrm{GEN}_{\mathrm{Q}} \cap \mathrm{f}(\mathrm{w})^{\cap \mathrm{g}(\mathrm{w})}(\Phi)\right]=1$ iff $\forall \mathrm{w}^{\prime} \in \cap \mathrm{f}(\mathrm{w})^{\cap \mathrm{g}(\mathrm{w})}\left[\Phi\left(\mathrm{w}^{\prime}\right)\right]=1$

According to $(27), \mathrm{GEN}_{\mathrm{Q}}(\Phi)$ is true in w with respect to the modal base $\mathrm{f}(\mathrm{w})$ iff $\Phi$ is true in all worlds $\mathrm{w}^{\prime}$ in the modal base ordered in terms of their closeness with respect to a set of ideal worlds in which some facts holding in $\mathrm{w}$ are a norm.

The strength of my analysis lies in the fact that it accounts for several observations: (a) the fact that $\mathrm{GEN}_{\mathrm{Q}}$ is only compatible with imperfective aspect; (b) stativization and non-accidentalness, as the event is a norm for the Agent; (d) quasi-universal force of generic quantification (Krifka et al. 1995); the intuition that GEN is quasi-universal follows from the fact that worlds in the $\mathrm{MB}$ are ordered with respect to a set of ideal worlds in which the content of the MB is a norm.

The analysis in (27) applies to all bare quantificational habituals, independently of whether they have an IS object (28a) or not (28b).

a. Mary washes a shirt very carefully/with a special soap.

b. Mary washes this shirt very carefully/with a special soap.

The IS in (28a) gives rise to an additional "in-virtue-of' inference typical of IS generics (Greenberg 2002): washing the object carefully is a norm for Mary in virtue of the Object's property of being a shirt. 
Focus-induced tripartite structures like that in (29) give rise to an additional performative deontic flavour. Performative modals are defined by Portner (2009) as those modals whose (implicit or explicit) presence in a declarative sentence results in the sentence performing a speech act different from, or in addition to, the usual speech act of assertion.

(29) Marie /LAve/ une chemise, elle ne la jette pas.

Mary /WAshes/ a shirt, she does not throw it away.

In sentences with a focused verb in the middlefield, the performative deontic flavour is either a denial (if the previous speaker said that Mary throws (dirty) shirts away) or it constitutes a covert piece of advice: Mary's norm should be yours too. These deontic flavours are allowed by a normative, thus deontic, OS, whether inverse or not. ${ }^{8}$

\section{Non-quantificational habituals: stativity and epistemic modal flavours}

Non-quantificational habituals are binary structures in which the subject $\mathrm{NP}$ is assigned topic function while the VP conveys informational focus. The subject NP of habituals is not quantifiable. As has been shown in section 2.2, the IS of non-quantificational habituals has "apparent wide scope" (except in the case of "pseudo-incorporated" IS ( $c f$. note 4 ). Thus, the verb is the only potential source of pluralization.

I follow Kratzer (2007) in assuming that verbs are "born as plurals" (see section 2.2) and I restrict this assumption to activity-like verbs in order to exclude pluractionals and telic iteratives. This allows us to assign a habitual reading to a sentence like (30a). However, the habitual reading of (30a) sounds somewhat strange in comparison with the habitual reading in (30b) and (30c).
a. Marie nettoie une casserole/lave une chemise. (EPIS/?? $\mathrm{HAB}$ ) Mary cleans a pan/washes a shirt.
b. Marie nettoie un bureau.
(EPIS/HAB)
Mary cleans an office.
c. Jean escorte un ministre.
John escorts a minister.
(EPIS/HAB)

The point is that the habitual reading of binary sentences with IS objects is extremely restricted. As observed in Mittwoch (2005), the "best" habituals with IS objects are those whose VP denotes a professional occupation, or at least can be interpreted as such $(30 \mathrm{~b}, \mathrm{c})$. The habitual reading of sentences with

8. Focus-induced generic quantification gives rise to an additional subjective component. This component can be implemented e.g. along the lines of Mari (2008). 
purely verbal predicates is somewhat less restricted, but still highly constrained too. While (31a) appears as "perfect" habitual, this is not the case for (31b).

a. Marie fume.

Mary smokes.

b. Marie pleure/rit/marche.

Marie cries/laughs/walks.

(EPIS/???HAB)

Relying on Landman \& Rothstein (2010) (henceforth L\&R 2010), I assume that the non-quantificational habitual reading is a stative reading of a predicate with an activity-like VP. According to L\&R (2010), both activities and states are incrementally homogeneous, which means that they both have a subinterval property. States differ from activities in that they are also segmentally homogeneous, i.e. a stative predicate is true at any minimal interval of its running time down to points. As for activities, they are segmentally heterogeneous, i.e. activity-like predicates are not required to hold at any point of their running time for the sentence to be true. That is the reason why activity-like predicates allow pause-stages and hence a plural reading (sum reading) ( $c f$. section 3.1).

On L\&R's (2010) approach, the stative (habitual) reading of predicates with activity-like VPs is due to what is called "gnomic-episodic ambiguity" ( $c f$. Carlson 1995 on generics), that is, the property of the event type to be unspecified for one of two values. It follows, roughly, that the habitual reading is just a STATIVE reading of a predicate with an activity-like VP. What distinguishes lexical statives from habituals is that the latter trigger the inference to their "episodic event witnesses" (L\&R 2010), whose distribution over time varies from context to context.

I will assume that there are two possible analyses of the habitual (stative) reading in sentences like (30)-(31). The first one is inductive. This analysis assumes that stativization is yielded by generalization and it consists in deriving a state from the observation of episodic events ( $c f$. Carlson's 1995 inductive approach to generics). The second analysis is deductive. In line with L\&R (2010), this analysis directly assigns a stative reading to an acivity-like predicate, which triggers the inference to "episodic event witnesses" of the sate in point.

I will assume that, on both approaches, stativity in non-quantificational habituals involves the operator STATIVE (STAT). I propose that in both cases this operator is responsible for the restrictions that hold for habituals like in (30) and (31). This operator can be realized in two different ways: the first one is inductive $\left(\mathrm{STAT}_{\text {IND }}\right.$ ) and the second one is deductive $\left(\mathrm{STAT}_{\mathrm{DED}}\right)$. $\mathrm{STAT}_{\text {IND }}$ is a modal quantifier over worlds. STAT ${ }_{\text {DED }}$ is not a modal quantifier itself. Yet, it triggers a covert epistemic modal MUST giving access to "episodic event witnesses" in terms of a reasoning like: if there is a state $e$ s.t. $P_{\text {stative }}(e)$, there MUST BE some events $e^{\prime} P_{\text {episod }}\left(e^{\prime}\right)$. 
STAT $_{\text {IND }}$ quantifies over worlds in its modal base MB restricted by an ordering source OS. I propose that the $\mathrm{MB} \cap \mathrm{f}(\mathrm{w})$ of $\mathrm{STAT}_{\mathrm{IND}}$ is circumstantial ("in view offacts in w"). This implies that $\mathrm{STAT}_{\text {IND }}$ requires that some verifying instances (at least one) of the event be realized in the actual world. In sentences like $(14 \mathrm{~b}, \mathrm{c})$ repeated in $(32)$ one occurrence of the event in the actual world turns out to be sufficient.

a. Marie fume, je t'assure. Je l'ai vue fumer hier à la fête.

Mary smokes, I assure you. I saw her smoke yesterday at the party.

b. Regarde ! Notre premier ministre se teint les cheveux.

Look! Our Prime Minister dyes his hair.

I propose that the ordering source $\cap \mathrm{g}(\mathrm{w})$ of $\mathrm{STAT}_{\mathrm{IND}}$ is stereotypical. According to Kratzer (1981), a stereotypical OS orders worlds in the MB with respect to those ideal worlds that correspond to a "normal course of events". A stereotypical OS belongs to the family of epistemic modalities ("in view of what is known"). I propose that the OS of $\mathrm{STAT}_{\mathrm{IND}}$ orders worlds in the MB with respect to those ideal worlds in which some facts that hold in w satisfy a set of stereotypical categories of HABITS which are known in w, e.g. work, hobby, bad/good habits, appearance, etc.

$\left[\mathrm{STAT}_{\mathrm{IND}} \cap \mathrm{f}(\mathrm{w})^{\cap \mathrm{g}(\mathrm{w})}\right]$ is defined iff $\cap \mathrm{f}(\mathrm{w})$ is circumstantial and

$\cap \mathrm{g}(\mathrm{w})$ is stereotypical.

$\left[\operatorname{STAT}_{\text {IND }} \cap \mathrm{f}(\mathrm{w})^{\cap \mathrm{g}(\mathrm{w})}(\Phi)\right]=1$ iff $\forall \mathrm{w}^{\prime} \in \cap \mathrm{f}(\mathrm{w})^{\cap \mathrm{g}(\mathrm{w})}\left[\Phi\left(\mathrm{w}^{\prime}\right)\right]=1$

According to (33), $\operatorname{STAT}_{\mathrm{IND}}(\Phi)$ is true in w with respect to the modal base $\cap \mathrm{f}(\mathrm{w})$ iff $\Phi$ is true in all worlds $\mathrm{w}^{\prime}$ in the modal base ordered in terms of their closeness with respect to a set of ideal worlds in which some facts that hold in w belong to a set of stereotypical HABITS.

In $(30 \mathrm{~b}, \mathrm{c})$ and in (31a), the habitual (stative) reading is easily derivable, the reason being that activities at hand can be ranged under a stereotypical HABIT: professional occupation in $(30 \mathrm{~b}, \mathrm{c})$, bad habit in (31a). Notice that the derivation of the state $e . g$. in (30b) implies that the state of cleaning an office holds of Mary at any minimal interval, down to points, of the running time of the state. This implies that the underlying activities must be sufficiently relevant in order to be conceptualized as the state in which Mary finds herself. In (30a) and (31b), the stative reading appears problematic since a plurality of activities of cleaning a particular pan or washing a particular shirt is unlikely to be conceptualized as known category of HABITS even if Mary cleans her preferred pan daily. Deriving a state from an activity does not depend on the frequency or regularity of the event iteration but on being associated with a known (stereotypical) set of HABITS.

STAT $_{\text {DED }}$ applies when the predicate is directly assigned stative meaning. STAT ${ }_{\mathrm{DED}}$ is not modal itself. It is a state like other states. A sentence 
with a stative predicate (Mary loves John) is just either true or false. However, unlike other statives, STAT $_{\text {DED }}$ triggers a covert strong epistemic modal MUST which gives access to "episodic event witnesses" located in a set of possible worlds. STAT ${ }_{\text {DED }}$ is promoted if the predicate is directly interpreted as denoting "what is known" instead of "what is observed", e.g. contractual duties (work), abilities, dispositions.

The MB of epistemic MUST is epistemic ("in view of what is known"). "What is known" in this case is e.g. the knowledge that Mary's contractual duty is the cleaning of an office independently of whether activities of cleaning are performed or not; speaking French is John's ability independently of whether this ability is realized or not, etc.

The MB of epistemic MUST contains "what the speaker knows in w", e.g. the speaker knows that Mary has such and such contractual duty, such and such ability or disposition. ${ }^{9}$ The $\mathrm{OS} \cap \mathrm{g}(\mathrm{w})$ is stereotypical. It orders worlds in the MB with respect to those ideal worlds that satisfy our "reasonable expectations", i.e. those worlds in which duties, abilities and dispositions are realized. MUST $_{\text {epist }}$ universally quantifies over worlds in the MB restricted by OS.

$$
\begin{aligned}
& \text { STAT }_{\text {DED }} \rightarrow \operatorname{MUST}_{\text {epist }} \\
& {\left[\operatorname{MUST}_{\text {epist }} \cap \mathrm{f}(\mathrm{w})^{\cap \mathrm{g}(\mathrm{w})}\right] \text { is defined iff } \cap \mathrm{f}(\mathrm{w}) \text { is epistemic and } \cap \mathrm{g}(\mathrm{w}) \text { is }} \\
& \text { stereotypical. } \\
& {\left[\operatorname{MUST}_{\text {epist }} \cap \mathrm{f}(\mathrm{w})^{\cap \mathrm{g}(\mathrm{w})}(\Phi)\right]=1 \text { iff } \forall \mathrm{w}^{\prime} \in \cap \mathrm{f}(\mathrm{w})^{\cap \mathrm{g}(\mathrm{w})}\left[\Phi\left(\mathrm{w}^{\prime}\right)\right]=1}
\end{aligned}
$$

According to $(34), \operatorname{MUST}(\Phi)$ is true in $w$ with respect to the modal base $\cap \mathrm{f}(\mathrm{w})$ iff $\Phi$ is true in all worlds $\mathrm{w}^{\prime}$ in the modal base ordered in terms of their closeness with respect to a set of ideal worlds in which duties, abilities and dispositions are realized.

Sentences quantified by STAT $_{\text {IND }}$ under imperfective aspect easily combine with perfective aspect. However, perfective aspect cancels modal quantification over worlds by locating the whole state in the actual world. For this reason the requirements on truth conditions of the habitual reading under perfective aspect are purely extensional: sufficient number of episodic events and sufficient time span. Imperfective aspect cancels these requirements $(c f$. section 3.1).

As for $\mathrm{STAT}_{\mathrm{DED}}$, future-oriented categories, viz. abilities and dispositions, require imperfective aspect. For instance, while (35a) can be interpreted as referring to ability, the truth of $(35 \mathrm{~b})$ requires that there be verifying instances of the event. Contractual duties are less demanding in this respect. The existence of a contract as such suffices to make these statives true as it is the case in somewhat adapted Krifka's et al. example (35c).

9. $\quad C f$. Hacquard (2007) on speaker-orientedness of epistemic modals. 
a. Jean parle le chinois. John speaks Chinese.

b. Jean a parlé le Chinois pendant dix ans. John spoke.PC Chinese for ten years.

c. Mary handled the mail from Antarctica. Since there was no such mail, she was dismissed after three months.

What is said above applies to non-quantificational habituals, that is habituals with one of the following features: (a) IS objects, which are the most severely restricted; (b) purely verbal predicates; though less restricted than (a), a lot of constraints still apply to them; (c) sentences with bare singular object NPs (in English), pseudo-incorporated IS (Mary wears a hat/Marie porte un chapeau, $c f$. note 5) and weak definites (Marie joue du piano/ Mary plays DU_piano).

Habituals with existential bare plurals in English and des-plurals in French are not non-quantificational. Existential bare plurals and des-plurals have distributive properties and are much less dependent on stereotypical stativizing categories. I hypothesize that sentences with existential plural object NPs constitute a third category of habituals. Examples that illustrate this most typical and numerically strongest group of habituals seem to require a restrictor provided externally by the context so that their whole VP maps onto the nuclear scope of a covert quantifier. Krifka's et al. (1995) central hypothesis concerning the need of contextually relevant situations is probably based on this category of habituals.

\section{Conclusion}

The analysis leads to the conclusion that habituals do not constitute a homogeneous class. I have shown that the "natural" presence or absence of an internal covert quantifier depends on whether the structure of the sentence is tripartite or binary. I have argued that habituality consists of two components: an extensional component and an intensional (modal) component. The intensional component is licensed by the imperfective aspect. Perfective aspect deprives habituals of their modal component. What remains then is only their extensional component. My analysis shows that the modal difference between these two types of habituals is not only due to their respective modal quantifiers but also to their ordering sources which give them different modal flavours: deontic flavour in quantificational habituals and epistemic flavour in non-quantificational habituals. 


\section{REFERENCES}

AnAnd, Pranav; Hacquart, Valentine (2011). The role of the imperfect in Romance counterfactuals. $S u B$ 14: 37-50.

Boneh, Nora; Doron, Edit (2008). Habituality and the habitual aspect. In Rothstein, S. (ed.) Theoretical and Crosslinguistic Approaches to the Semantics of Aspect: 321-347. Amsterdam: Benjamins.

BoneH, Nora; Doron, Edit (2010). Modal and temporal aspects of habituality. In RappaportHovav, M.; Doron, E. \& Sichel, I. (eds.) Syntax, Lexical Semantics, and Event Structure: 338-362. Oxford: Oxford University Press.

Büring, Daniel (2001). What do definites do that indefinites definitely don't? In Fery, C. \& Sternefeld, W. (eds) Audiatur Vox Sapentiae-A Festschrift for Arnim von Stechow: 70-100. Berlin: Akademie Verlag.

CARLson, Gregory N. (1995). Truth conditions of generic sentences: Two contrasting views. In Carlson, G. N. \& Pelletier, F. J. (eds.) The Generic Book: 224-237. Chicago: University of Chicago Press.

CARLson, Greg N. (2006). The meaningful bounds of incorporation. In Vogeleer, S. \& Tasmowski, L. (eds) Non-definiteness and Plurality: 35-50. Amsterdam: Benjamins.

Cohen, Ariel (2003). How does focus affect logical form? In Falk, Y. (ed.) Proceedings of IATL : 19. Available at http://micro5.mscc.huji.ac.il/ english/IATL/19.TOC.html

Comrie, Bernard (1976). Aspect. Cambridge: Cambridge University Press.

Condoravdi, Cleo (1989). The middle: Where semantics and morphology meet. In Branigan, Ph. (ed.) MIT Working Papers in Linguistics: 16-30. Cambridge (Mass): MIT Press.

DAHL, Östen (1975). On Generics. In Keenan, E. L. (ed.) Formal Semantics of Natural Language: Papers from a Colloquium Sponsored by the King's College Research Centre: 99-111. Cambridge: Cambridge University Press.

DAHL, Östen (1995). The marking of the episodic/generic distinction in tense-aspect systems. In Carlson, G. N. \& Pelletier, F. J. (eds.) The Generic Book: 412-425. Chicago: University of Chicago Press.

FERrEIRA, Marcelo (2004). Imperfectives and plurality. In Young, R. (ed.) SALT XIV : 74-91. Ithaca, NY: Cornell University.

FERREIRA, Marcelo (2005). Bare habituals and plural definite descriptions. In Maier, E.; Bary, C. \& Huitink, J. (eds.) Proceedings of SuB 9. Available at www.ru.nl/ncs/sub9.

Greenberg, Yael (2002). Two types of quantificational modalized genericity and the interpretation of bare plurals and indefinite singular NPs. In Jackson, B. et al. (eds.) Proceedings of SALT XII: 104-123.

HaCquard, Valentine (2007). Speaker-oriented vs subject-oriented modals: A split in implicative behavior. $S u B$ 11: 305-319.

KLEIBER, Georges (1987). Du côté de la référence verbale. Les phrases habituelles. Bern: Peter Lang.

Kratzer, Angelika (1981). The notional category of modality. In Eikmeyer, H.J. \& Rieser, H. (eds...) Words, Worlds, and Contexts: New Approaches to Word Semantics: 38-74. Berlin: de Gruyter.

Kratzer, Angelika (1989). An investigation of the lumps of thought. Linguistics and Philosophy 12: 607-653.

Kratzer, Angelika (2004). Telicity and the meaning of objective case. In Guéron, J. \& Lecarme, J. (eds.) The Syntax of Time: 389-423. Cambridge (Mass): MIT Press. 
Kratzer, Angelika (2007). On the plurality of verbs. In Dölling, J. \& Heyde-Zybatow, T. (eds.) Event Structures in Linguistic Form and Interpretation: 269-300. Berlin: Mouton de Gruyter.

KRIFKA, Manfred et al. (1995). Genericity: An introduction. In Carlson, G. \& Pelletier, F. J. (eds.) The Generic Book: 1-124. Chicago: Chicago University Press.

LACA, Brenda (1990). Generic objects: some more pieces of the puzzle. Lingua 81: 25-46.

LANDMAn, Fred (1992). The progressive. Natural Language Semantics 1: 1-32.

LANDMAn, Fred; Rothstein, Susan (2010). Incremental homogeneity in the semantics of aspectual for-phrases. In Rappaport-Hovav, M.; Doron, E. \& Sichel, I. (eds.) Lexical Semantics, Syntax, and Event Structure: 229-251. Oxford: Oxford University Press.

Lenci, Alessandro; Bertinetto, Pier-Marco (2000). Aspect, adverbs, and events. In Higginbotham, J.; Pianesi, F. \& Varzi A. C. (eds.) Speaking of Events: 265-287. Oxford: Oxford University Press.

LinK, Godehard (1983). The logical analysis of plurals and mass terms. In Baüerle, R.; Schwarze, C. \& von Stechow, A. (eds.) Meaning, Use, and Interpretation of Language: 302-323. Berlin: de Gruyter.

Mari, Alda (2008). Analicity under perspective: indefinite generics in French. In Grønn, A. (ed.) Proceedings of SuB 12: 414-429.

Miтtwoch, Anita (2005). Unspecified arguments in episodic and habitual sentences. In Erteschik-Shir N. \& Rapoport, T. (eds.) The Syntax of Aspect: 237-254. Oxford: Oxford University Press.

Portner, Paul (1998). The progressive in modal semantics. Language 74: 760-787.

PorTner, Paul (2009). Modality. Oxford: Oxford University Press.

Rimell, Laura (2004). Habitual sentences and generic quantification. WCCFL 23: 663-676.

Steinbach, Marcus (2002). Middle Voice. A Comparative Study in the Syntax-Semantics Interface of German. Amsterdam: Benjamins.

\section{RÉSUMÉ}

Cette étude porte sur les phrases habituelles nues avec des objets indéfinis singuliers. Le terme d'habituels nus désigne les phrases habituelles qui ne contiennent pas d'adverbes de quantification. À partir des ces phrases, nous défendons l'idée que la classe des habituels se compose de deux groupes différents: les habituels quantificationnels et les habituels non quantificationnels. L'article met en évidence la distinction entre ces deux types, au niveau extensionnel en termes de leur interaction avec l'aspect et au niveau intensionnel en termes de leur composant modal respectif à l'origine de la généralisation.

\section{Mots-CLÉS}

Habituels nus, objets indéfinis singuliers, pluralité verbale, aspect, quantification modale, source d'ordre. 
